\title{
BIOLOGIA E ESTẢGIOS IMATUROS DE NEOCLYTUS CURVATUS (GERMAR) (COLEOPTERA, CERAMBYCIDAE)
}

ANGÉLICA MARIA PENTEADO-DIAS

\section{ABSTRACT}

Larval and pupal stages of Neoclytus curvatus (Germar) are described and compared with other immature Clytini. Notes on the biology of the species are added.

O material estudado é procedente de São Carlos, SP e foi identificado por Ubirajara R. Martins, do Museu de Zoologia da Universidade de São Paulo, a quem agradeço.

\section{LARVA (figs. 1-2)}

Comprimento total $15,5 \mathrm{~mm}$, em média; comprimento do protórax 1,75 $\mathrm{mm}$, em média; largura do protórax $3,87 \mathrm{~mm}$, em média.

A larva de Neoclytus curvatus difere daquela de $N$. pusillus por apresentar ocelos mais pigmentados, largura da cabeça maior em relação à largura do protórax e processo suplementar da antena (fig. 1) ligeiramente maior e mais acuminado. Difere daquela de $N$. cacicus, bem como de outras assinaladas por Duffy (1960) por não ter o palpo labial com o segmento II muito mais curto que o I (fig. 2).

PUPA (figs. 3-4)

Comprimento total 11,4 $\mathrm{mm}$, em média; compriment. do protórax 2,1 $\mathrm{mm}$, em média; largura do protórax $2,3 \mathrm{~mm}$, em média.

A pupa de $N$. curvatus difere daquela de $N$. centuric por apresentar tergitos abdominais I-VI com fileira transversal de espir os; $N$. centurio os apresenta dispostos em fileira transversal nos tergitos II-VI (Duffy, 1960). Difere da pupa de $N$. pusillus por não apresentar, comc aquela, borło anterior do pronoto mais saliente (fig. 1) e ápice dos élitros cor esł inhos desenvolvidos (Penteado-Dias, 1979) (fig. 4).

\section{BIOLOGIA (figs. 5-8)}

A partir dos ovos postos por uma fêmea e'r janeiro de 1982 foram obtidos adultos de julho a outubro do mesmo ans.

A criação deu-se em laboratório e as larvą nutriram-se de Delonix sp. (Leguminosae). Lima (1955) refere-se a Pyrus communis (Rosaceae) como planta hospedeira para essa espécie.

Os ovos são brancos, elípticos (fig. 5), me_em aproximadamente $1,5 \mathrm{~mm}$ de comprimento e são colocados em frestas sob a casca. As larvas jovens constroem inicialmente galerias subcorticais (Juffy, 1953) (fig. 6) para depois as aprofundarem e as alargarem. Essas galerias são construídas no sentido longitudinal do ramo.

As câmaras pupais (fig. 7), internas e diretas (Duffy, 1953) medem aproximadamente 3,0 cm de comprimento. Para construí-las, as larvas utilizam uma das extremidades de sua galeria. Atingindo a fase adulta, o inseto emerge por um orifício circular (fig. 8), com aproximadamente $3,0 \mathrm{~mm}$ de diâmetro.

Departamento de Ciências Biológicas, Universidade Federal de São Calos, C. Postal 384, 13.560, São Calos, SP. 

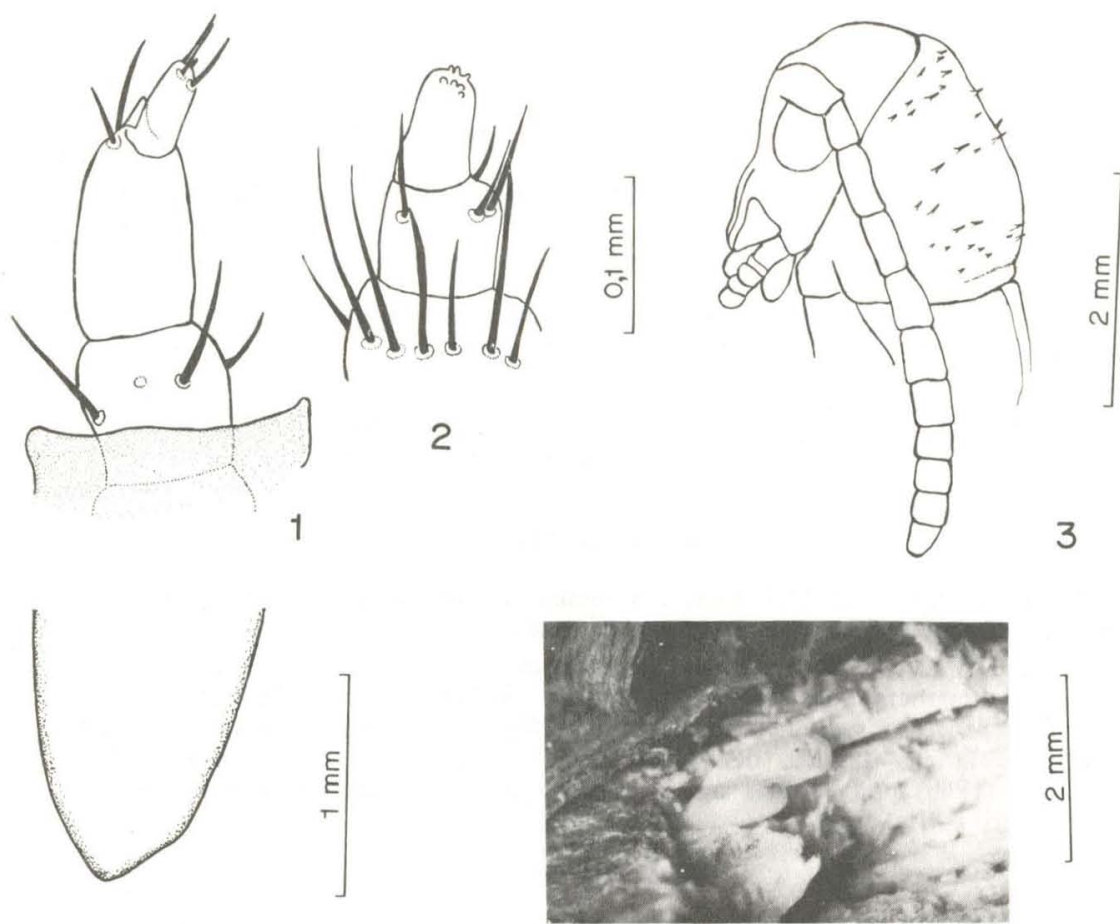

5

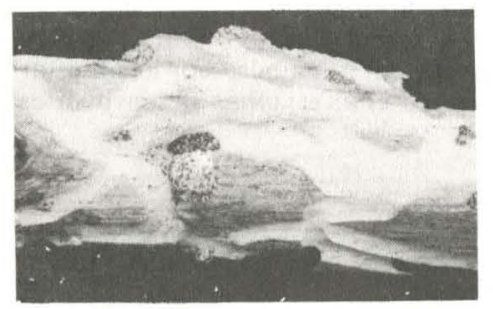

6
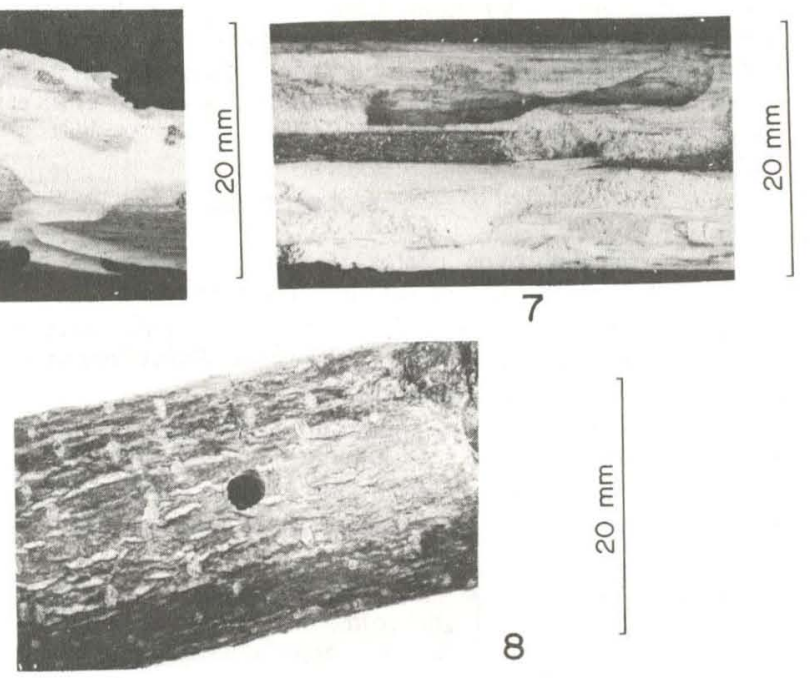

8

Neoclytus curvatus. Larva: 1, antena; 2, palpo labial. Pupa: 3, pronoto (vista lateral); 4, ápice do élitro esquerdo. Biologia: 5, ovos; 6, galerias larvais superficiais; 7, câmara pupal; 8 , orifício de emergência. 


\section{REFERENCIAS}

Duffy, E. A. J., 1953. A monograph of the immature stages of British and imported timber beetles (Cerambycidae), viii + 350 pp., British Museum (Natural History), London.

Duffy, E. A. J., 1960. A monograph of the immature stages of Neotropical timber beetles (Cerambycidae), vii +327 pp. British Museum (Natural History), London.

Lima, A. da Costa, 1955. Insetos do Brasil. Coleópteros. 9. ${ }^{\circ}$ tomo, 3. ${ }^{\mathrm{a}}$ parte. Escola Nacional de Agronomia. Série didática n. ${ }^{\circ} 11,289$ pp.

Penteado-Dias, A. M., 1979. Biologia e ontogenia de Neoclytus pusillus (Lap. \& Gory) (Coleoptera, Cerambycidae, Cerambycinae, Clytini). Revta bras. Ent. 23(2): 77-83. 